\title{
Behavior-Based Perceived Leadership Styles as Determinants of Organizational Functionality
}

\author{
Kinza Khan ${ }^{1}$, Nadeem Uz Zaman*2, Bilal Sarwar ${ }^{3}$ \& Hadi Hassan Khan ${ }^{4}$ \\ 1,2,3,4 Balochistan University of Information Technology, Engineering and Management Sciences, Quetta, \\ Pakistan
}

\begin{abstract}
This study aimed at exploring how the perception about leadership styles affected the functionality of the Higher Education Institutions. We used a self-administered questionnaire to a sample of 328 administration and faculty members of several public sector universities. The data collected were analyzed through structural equation modeling in AMOS 26. We found significant results between autocratic and democratic leadership styles as determinants of organizational functionality; such that the perceived autocratic leadership style negatively affected organizational functionality and the perceived democratic leadership style positively affected organizational functionality. The effect of laissez-faire was however statically insignificant. We thus conclude that the perception of a democratic leadership style improves organizational functionality; whereas, the perception of autocratic leadership negatively affects organizational functionality. Practically, the study shows as the employees are given the right to participate in the matters of a higher education institution, the organization becomes more functional.
\end{abstract}

Key words: Organizational leadership, functional leadership, dysfunctional leadership, implicit leadership theory.

\section{Introduction}

In this study, we have tried to explore how the perception of a leadership style affects the working culture or the functionality of an organization. The literature on leadership suggests great influence on the social and cultural environment of any organization (Chemers, 2014). Perceived leadership style on the other hand has been given little attention by the researchers. The concept of perceived leadership styles suggests that every individual in an organization can form a different perception about the leadership style of his or her supervisor or senior (Forsyth and Burnette, 2010).

Organizational functionality is primarily defined as the proper working of individuals as per the required norms and standards of the organization (Thompson, 2013). Thus, an organization going on as per the required standards may be termed as functional or otherwise dysfunctional.

* Corresponding author.

Email: naz_e_zeest@yahoo.com

http:/ /www.jbrc.pk 
The role of leadership is shaping organizational functionality, which cannot be ignored and so is the role of perceived leadership styles.

Many studies on dysfunctional organizations investigated the question with various variables and approaches. A deeper review of dysfunctional literature shows that the problem has been examined about individual conducts in the labor market (López-Domínguez et al., 2013). Research based on human actions suggests that interpersonal instability stems from individuals' dissatisfaction in corporate settings. Any research relies on particular medical disorders, psychological characteristics, and social environments in the workforce among people associated with aggression or behavioral issues (Griffin and Moorhead, 2011).

Other studies offer a more comprehensive summary of the harmful inferences of "counterproductive actions" by individuals about organizational roles (Levine and Moreland, 2012). All areas of study concentrate on what people with mental disorders do to company dysfunctions. Even organizations free of individual behavioral problems in the workplace may always have these individuals and organizational dysfunctions. Although it is challenging to deal with behavioral challenges, those actions' primary effect is a positive one (Alemu et al., 2016).

\subsection{Problem Statement}

The central concern or issue this study addresses is about the role of perceived leadership in determining the organizational functionality. At the beginning of the 20th century, there arose a "trend" about organizational Culture in the management field. Organizational culture is a unifying tool for transforming an organization, but its intensity may affect efficacy and achievements or shortcomings crucially. Interpersonal culture abstract arguments are evident in the irony that an organization has an organizational culture and a culture (Domagała, 2017). There arose the concept of organizational functionally.

Besides, Organizational Functionality can be defined as the shared, basic assumptions an organization has learned while dealing with and resolving the environment and performing in efficient ways. External adaptation and internal integration problems that new members are taught are the right way to solve them. That organization has its own unique culture that evolves overnight in two dimensions to represent its identity: visible and invisible. A better functioning organization's visual aspect is expressed in its espoused principles, ideology, and purpose. Simultaneously, the hidden component resides in the unspoken set of values that govern the organization's employees' behavior and expectations (Al-Alawi and Alkhodari, 2016). The effect is that institutions become unstable, not only because of their internal contradictions but also because of an organization's interaction with its environment. Therefore, we consider that there is a need for studying the effect of the perceived leadership styles on the functionality of public sector universities.

Should the perceived leadership style in universities be considered while studying, them being functional? Unfortunately, it has been observed the leadership factor has been understudied with basically the unpleasant effects while seeing it as the mentoring factor in organizational settings (Harper et al., 2015). However, academia's leadership factor plays a vital role in employing its everyday running (Fullwood et al., 2013). Likewise, any other organization, universities are affected by the type of leadership responsible for its operations.

"With organizational life's increasing complexity, confusion and dynamism, organizational dualities and the latent contradictions they spawn are becoming more common" (Ashforth et al., 2014). The analysis of the subject literature concludes that organizational Culture, which can be described as "organizational standards and expectations about an organization's actions and 
conduct," will inevitably promote the development and maintenance of such a working environment (Aarons et al., 2012).

Using this strategy, each company will decide how procedures arise, fix problems, establish habits, and unify intervention strategies, ensuring that the enterprise's dysfunctions are avoided. The influence of the circumstances under which Culture is thriving in the running of an organization. It should be thus consciously established and encourage the correct practices, the achievements and the risks involved with the everyday activities of a business underlined and the reality that any part of the organization takes place at all stages, which helps to prevent long-term disturbances and anomalies in the organization's actual functioning.

\subsection{Significance of Study}

This study is relevant to the target sector as formal leadership is still in a state of ferment (Alvesson and Sveningsson, 2015). How employees perceive their leaders and associate the functionality of their organization will be studied. We can see how perception is related to shaping an employee's performance (Cook and Beaven, 2013). Organizations with high-level functionality often attribute to the type of leadership present (Müller and Turner, 2010). That type of leadership, being practiced, will indicate that it is making the organization functional or dysfunctional (Oreg and Berson, 2011). Leadership is a crucial factor for any organization's growth and performance. Efficient leadership competencies and attributes guarantee an organization's performance when weak management competencies and practices contribute to the individual company's collapse. The presumed leadership traits dependent on actions have been seen to guarantee harmony, communication, good efficiency, and a high standard of services resulting in an organization's effectiveness.

A good leader boosts an institution's performance and vice versa (MalekalketabKhiabani and Abdizadeh, 2014). In the current day, there are huge variances amid the leaders of the functional and dysfunctional organization (Alemu et al., 2016). Your working style depends on the structure of your organization. The corporate structure defines your role, responsibilities, and Culture of work. The system requires an office, posting, hierarchy, etc. (Marquardt, 2011).

For maximum efficiency, organizations require good leadership. As we recognize, leadership is a function both incorporated and worthy of being learned. Leadership in companies discusses individual and professional psychology. Interpersonal organizations rely on improving organization appropriate leadership qualities and abilities. This means that people have the potential to confront and grow during difficult times in the industry. The supervisors are precisely defined and differentiated. The member will be able to manage the party of citizens (Müller and Turner, 2010).

A perfect business chief does not control anyone. This will lead people under him and give them a sense of purpose to accomplish corporate goals and behave responsible. He ought to be confident without a doubt. He would be empathic and consider the group's needs. A corporate chief can direct many and coordinate collective behavior (DeRue and Ashford, 2010).

As organizational leaders, extremely ambitious individuals with a high energy level, a drive for self-esteem, intelligence, thorough work knowledge, are honest and flexible. Leadership develops knowledge and expertise in leadership, effective collaboration, dispute management, and community problem-solving strategies. Organizational leaders communicate organizational purpose, vision, and goals, build staff trust, operate efficiently, aid workers in the organizations' efficient development, and contribute to their goals (Hu Juneja, 2011).

A supervisor is superior in the organizational setting and the leader of his group of aides. 
That includes the managing director trying to make sure the employees collaborate to accomplish departmental or organizational goals. Hence, the boss needs to step in and assume action as chief if there are issues (DeRue and Ashford, 2010).

Members, executives, and staff of companies significantly impact the working environment's culture and efficacy. The interpretation is how we all perceive our interactions. It's a significant and demanding aspect of human conduct; supervisors will understand that everyone has different standards. People do not necessarily stand out when they try to serve their ideals. People do not necessarily follow as their beliefs suggest. You do something you think to reflect your beliefs. Secondly, it implies that the brain's understanding of an event and its behavior often has a time difference. Thirdly, the trial over this period is what can be used as a perception (Otara, 2011).

Mostly, people think they are efficient and successful members, but they might have a somewhat different opinion about their perceived supporters. Berelson and Steiner (1964), in their book Human Behavior explain cognition as a dynamic mechanism through which people choose sensory stimuli and assemble them into a cohesive and rational representation of the environment. We respond to such conditions based on what we think rather than what it is. We always see only what we expect to see in a particular circumstance. And the way we react depends, not just on what has been told, but on what we feel. Sensitivity is just another opportunity that a person uses to develop the real urge to be the best he/she might have. By using all available tools, we can achieve great things with our employees (Elliott, 2012).

To executives as well as philosophers, the issues of corporate success and failure are essential. This article has shown that the Framework of Organizational Growth has empirical support. It can be used as a meaningful lens for managers to plan future organizational development. This opens the way for researchers to new questions and problems. Although it does not address all issues in this field in full, we conclude that this article provides the foundation for a new course in research and management practice that can potentially be of significance (Flamholtz and Randle, 2015).

The research will be directed to the universities present in Quetta and will see how the leadership factor makes them functional or dysfunctional. Leadership is a very imperative position in any organization, and the study will help us find out what we want them to do and be as they lead us (Alemu et al., 2016). The leadership role will be evaluated against the characteristics from the perceived leadership theory, which will give us insight into their roles from different dimensions, i.e., their personality, ethical behavior, use of power, and negligence. And a study on this area will help better the role of leadership in making academic leadership more purposeful.

\subsection{Study Aims and Rationale}

The study aims to understand an organization being functional or dysfunctional through the leadership factor. This study will be evaluating the behavioral-based perceived leadership styles of the data collected and checking their functions related to them from the Higher Education Institutions present in Quetta. This will help us see how the leadership style will affect these organizations' functionality and dysfunctionality at a very small level as the most operative leadership role will be studied. The immediate supervisor and subordinate relationship will be studied. The practical implication of this research will be for individual leaders. The variables could serve these individual leaders to improve their style of leading their subordinates (Alemu et al., 2016). 


\section{Literature Review}

\subsection{Organizational Functionality}

The term functional is defined as having a practical use or working properly (Thompson, 2013). Functional organization is a form of organizational structure using the function or role based theory of specialization. It permits decision making to be decentralized because matters are delegated to specialized individuals or groups. It is up to them to implement, evaluate or control the procedures or objectives specified. According to the group's primary role, the functional organization includes the whole of the business (Boneh et al., 2011).

Among the structures designed to define leadership, the Functional Leadership System is one of them. Much leadership research was done, many researchers years back, have tried to identify what differentiates a trustworthy leader from the masses. The result is a large variety of theories. These are therefore graded according to the perspective of the study. Popular leadership analyzes theories of characteristics, behavioral theories, likelihood theories, transformation theories, transactional theories, great man theory, and functional theories (Kuijk, 2018).

Many studies on dysfunctional organizations investigated the question with various variables and approaches. A deeper review of dysfunctional literature shows that the problem has been examined about individual conducts in the labor market (López-Domínguez et al., 2013). Research based on human actions suggests that interpersonal instability stems from individuals' dissatisfaction in corporate settings. Any research relies on particular medical disorders, psychological characteristics, and social environments in the workforce among people associated with aggression or behavioral issues (Griffin and Moorhead, 2011).

Other studies offer a more comprehensive summary of the harmful inferences of "counterproductive actions" by individuals about organizational roles (Levine and Moreland, 2012). All areas of study concentrate on what people with mental disorders do to company dysfunctions. Even organizations free of individual behavioral problems in the workplace may always have these individuals and organizational dysfunctions. Although it is challenging to deal with behavioral challenges, those actions' primary effect is a positive one (Alemu et al., 2016).

The illusory visibility of corporate culture's meaning hides the underlying issues connected with knowing it. The multiplicity of its concepts is the source of its many terms in the literature of the topic, including "a set of values, rituals, objectives, opinions, and attitudes" (Wiseman et al., 2017), "a pattern of assumptions" (Schein, 2010), "individual invention" (Habib et al., 2014)," normative beliefs" (Domagała, 2017), "an organization's autonomous nervous system," "a network of meanings created by people in the organization phase," "a mutual development."

The assessment of an organization's stability is an incredibly demanding activity as it also requires very intense and complex dysfunctionality in specific ways. Interpersonal interactions with the individual itself, the company itself, and the organizations nature will be studied. Every organization has its various malfunctions, which show that organizational malfunctions are "anomalies that are defined as the deviations from the actual working of an organization compared to a model that works (Domagała, 2017). Dysfunctions can have many origins and exist in an institution's different areas. The established causes of dysfunctions include "the disruptions occurring during the execution of an organization's essential functions, the dysfunctions arising from the differentiation of goals or of perception or both, and the effect of this situation on the interaction between the organization's leadership and its followers (Schein, 2010).

While we use the terms "ability," "competence," and "efficiency interchangeably, we render other distinctions. In technological fields, we refer to a person's capability or an entity's core 
competencies; in social issues, we refer to a person's leadership capacity or an organization's potential (Ulrich and Smallwood, 2012). When a business delivers on its employees' combined competencies and abilities, it is said to have organizational functionality. While an individual may be technically proficient or possess leadership qualities, the company may or may not share these qualities. Corporate flexibility allows organizations to transform their methodology know-how into performance (If so, workers who succeed in these areas would certainly remain employed; if not, they will become frustrated.) A central communications expertise, for instance, does not bring benefit unless the company may trigger improvements (Ulrich and Smallwood, 2012).

Organizations are continually making assumptions about their plans. Prudent leaders make decisions based on a detailed examination of present and past conditions, as well as a careful examination of potential possibilities. The researcher has proposed a model and method that allow organizations and their leaders to research (Alemu and Shea, 2019). The methods that may diagnose in an organizational context are the current method to examine organizational status to assess whether improvements are required to improve the organization's performance (Alderfer, 1980).

There are several reviews and theoretical models for diagnosing organizations in the organizational diagnosis literature. Another area of study that uses diagnostic technique is the CSF as a critical organizational success factor (Alemu and Shea, 2019). Lavy et al. (2010) suggested that managers should pay attention and diagnose crucial elements that influence the organization's overall performance. Alemu and Shea (2019) (p. 1520) mentioned that "The McKinsey 7S Framework, the Leavitt Model, and the MIT 90 Model" are examples of organizational diagnosis models that come under this principle.

A strategic plan, common principles, employee skills, leadership style, organizational structure, processes, and staff are the seven components of the McKinsey 7S framework essential for organizational effectiveness (Zheng et al., 2010). Besides, Leavitt (1965) model defines four fundamental elements: personnel, structure, task, and technology, affecting organization operations. The MIT 90 model is similar (Morton et al., 2012). The different variables that determine the performance of an organization are proposed. Outside the environmental and research, and technological advancement, the internal factors include organizational strategy, architecture, procedures, staff, and infrastructure (Morton et al., 2012).

The open system model is the second approach to organizational assessment (OS). According to this OS theory, organizations and their performance are determined by what happens internally and by environmental conditions. For example, the "Weisbord six box model" used "six distinct but interrelated variables" to enhance comprehension and organizational functions (Kontić, 2012; Stoller et al., 2013). Goals, organization, relations, incentives, helpfulness, and leadership processes are examples of such variables, which consider the outside world's work. According to the Congruence Model, organizations are structures made up of interconnected components. The higher the degree of fit or congruence in the interaction phase, the more successful the organization is (Seong et al., 2015).

The technical, political-cultural model corresponds to the OS method presented by Tichy (1983). These three pillars of technological, political, and cultural elements must all work together for organizations to function effectively (Zare and SHEKARCHI, 2014). "Burke and Letwin's model," based on the OS model, are considered previous research literature and their own consulting experiences (Stone, 2015). Through the interaction of 12 variables, i.e. project and policy, external environment, ideology, organization and style, leadership, procedures, atmosphere, skills-to-work commitment, motivation, and performance, we hypothesize multi- 
directional, causal linkages. Human interests and values are encouraged.

Furthermore, they term their model a strictly empirical causal model and interpret rather than any data analysis. Gavrea's recent causal model examined linear relationships between several variables categorized into practice and output variables. The model developed by Gavrea et al. (2011) did not go beyond the quest for relationships and direct effects to become a detailed model.

As a result, this study aims to diagnose a newly developed model to investigate the organization's functionality and leadership, employees, the way tasks are carried out (Culture), and organizational structure and governance (Alemu and Shea, 2019). Route analysis, a form of structural equation modeling (SEM), may describe a model that represents the degree and complexity of the effects of the organizational functionality. Finally, a road diagram illustrating and explaining the meaning is shown. The study will also look at the direct and indirect effects of these influences on organizational performance and their implications for education.

Three assumptions guide the selection of these variables for the model. The first assumption is that all these factors (leaders, personnel, community, and organizational structure) exist in every organization. Studies on functionality should consider all of them. These variables were carefully chosen based on the literature and commonly used components of the organizational diagnosis models available.

Furthermore, almost all of today's leadership theories relate leadership to the achievement of organizational objectives. Although the methodology and focus of leadership literature vary, it is widely acknowledged that management is an important component in the study of organizational functionality. Numerous studies on the topic emphasize the importance of the correlation between leadership and corporate success, either directly or indirectly (Vigoda-Gadot and Meisler, 2010).

Similarly, some previous studies have focused on the role of workers/staff in achieving organizational objectives. Employee care and active engagement are critical for the achievement of organizational objectives (Alemu and Shea, 2019). Amah and Ahiauzu (2013) hypothesized employees' involvement in organizational functionality and discovered a positive connection between productivity of employee and effective organizations.

Deal and Kennedy (1983); Tichy (1983); Waterman Jr et al. (1980); Weisbord (1976) are examples of organizational diagnosis models that use culture as a predictor. Organizational culture is a commonly used feature of the organizational study. Although their methods and models vary slightly, authors such as Deal and Kennedy (1983); Kotter (2008); Martin (1992); Schein (2010); Waterman Jr et al. (1980) all argue that organizational culture influences organizational performance directly or indirectly. According to Lee and Yu, culture affects an organization's efficiency and the organizational processes in place (Zheng et al., 2010).

It is difficult to conceptualize entities that are missing from the structure; however, understanding their effect on the organization's functionality level depends on how it is understood first. According to Meijaard et al. (2005), the structure is perceived within an organization regarding the division of labor and management mechanisms. Burke and Litwin (1992) provide a more detailed organizational structure described as "The organization of activities and persons in specific fields and positions of accountability, decision-making power, management, and communication to ensure the task and policy of the company can be effectively carried out." A field that commanded the attention of some researchers was the organizational structure concerning success. The research found that a company's structure influences its efficiency in both immediate and non-economic terms (Mehmood et al., 2016). Hao et al. (2012) identified an indirect performance-structure relationship via creativity (top level managers) and organizational learn- 
ing (middle managers). Similarly, to achieve organizational objectives, emphasize the importance of organizational structure (Woodard, 2017). Even though leadership, personnel, culture, and structure are all important variables in the study of organizational diagnosis, none of these studies focuses on creating a research course model. Secondly, the two organizations' organizational efficiency with the same intent and capability in a similar setting that behaves differently because of internal factors in the organizations can be evaluated using the organization's internal variables. This is believed that an analysis of the extent of organizational functions utilizing internal variables within the business provides a more detailed appraisal and self-examination. It minimizes the noises generated by external variables. Therefore, in this study, all variables are deliberately chosen to be organization-specific. The third premise is that Organizational culture, staff, leadership, and an entity's control structure all have varying degrees of relationship with organizational performance; while assessing the degree and path of relationship impact is feature of current study.

\subsection{Implicit Leadership Theory}

In present days, leadership has become very significant in any management schema (Sadler, 2001). Leadership is both a field of research and practical ability to guide or "led" other individuals, teams, or entire organizations. Expert literature discusses different perspectives, comparisons between East and West leadership approaches, and (western) between the United States and European approaches. American academic environments define leadership as "a process of social influence in which an individual can attract help and support from others to perform a common task (Chemers, 2014).

Theories of situation, function, behavior, power, vision and values, charisma, and intelligence have been produced by management leadership studies (Chin, 2015). Functional leadership theory is a specific leadership theory expected to contribute to the organization's effectiveness or unit. This theory argues that the leaders' main task is to see that everything is taken care of for the group needs; therefore, if they have contributed to group effectiveness and cohesion, a leader can be said to have performed well. Leadership theories are developed through the study of successful leaders and the identification of actions and behaviors. Extensive studies with plenty of information enable leaders to correlate what they do with their successful results, i.e. their actions or functions. In the functional model, leadership is not centered on an individual but a set of community activities. Any group member can carry out such conduct so that every member can be part of leadership. The Functional Leadership Theory emphasizes how an organization and task are led than who is formally appointed (Hackman and Walton, 1986).

Although the leader is potentially at fault in chaotic situations, the author argues that various contextual factors cause success or failure. In essence, the leader is guilt-free. The three models/frameworks are specifically described to improve understanding of leadership disaster components (Walton, 2007). Management means working within the limits of the status quo, while leadership is more involved in seeing and attempting other, broader possibilities. However, to be effective, leaders must also be able to be managers (Govan et al., 2007).

It suggests at first glance that leadership is changing in universities and that university leadership needs to change. A second look may reveal additional ambiguities, especially related to the concept of' leadership.' Many people will consider leadership to be the domain of vicechancellors, doctors, professors, department heads, and functional heads such as registry, catering, or property. But leadership can also be understood as a widely spread role in an institution and extends beyond senior post-holders official roles and responsibilities. Other comments on 
the values and traditions of democracy and the college may find the notion of leadership itself strange in the context of universities (Middlehurst, 1995).

With the help of the studies available on the functional and dysfunctional organizations, keeping the leadership factor in view that is one of the very emerging and researched themes, a study on the public sector universities of Quetta will be carried out. The study's core purpose is to look into the organizations with a view of how leadership at different levels affects them. It has been studied that prosocial aspects affect the organizational settings making them dysfunctional or functional (Brief and Motowidlo, 1986). The study will direct us to explore the ways organizations respond to them in terms of stability.

\subsection{Implicit Leadership Theory}

Implicit Leadership Theory (ICT), founded by Robert Lord and his associates, is a theoretical leadership theory (Forsyth and Burnette, 2010). The theory is that people construct and use abstract models of the universe for their life and actions (Schyns and Meindl, 2005). ILT means that leaders of the party collectively anticipate specific characteristics and expectations. The word tacit is used because it is not articulated publicly, and the word hypothesis is used as the concept generalizes the perception of the past into current interactions (Forsyth and Burnette, 2010). ILTs allow individuals to recognize leaders and help leaders prevent conflicts (Schyns and Meindl, 2005).

\subsection{Individual Differences}

While ILTs differ among people, many overlap with mission and relationship skills. Leaders need to succeed (Forsyth and Burnette, 2010). Most people follow a leader with job skills who is in charge, committed, influential, and actively engaged in community activities. A person, who loves, is optimistic towards fresh ideas and engaging in community activity, while assessing partnership skills is desired by many people (Schyns and Meindl, 2005). The heterogeneity in content and factor structure in male and female ILTs was opposed by three factors: leaders, active leaders, and supervisors, in a report by Offermann et al. (1994). Eight ILT influences, among males and females and over the three stimuli, were found to become relatively stable. Such eight facets are elegance, reactivity, dedication, spirit, attractiveness, beauty, and dictatorship. While ILTs vary depending on the person, this study's results indicate that this variability may be systemic and, at times, predictable (Shondrick et al., 2010).

\subsection{Cultural Difference}

Although cultural credibility is respected, leadership prototypes' quality plays a significant role in society (Den Hartog, 2015). For example, a study started in 1991, which measured leadership prototypes in 60 countries, found that more individualistic cultures favor ambitious leaders, while collectives often prefer self-defeating leaders (Arrospide et al., NA). Cross-cultural differences may be possible.

Implicit leadership theories (ILTs) of followers are central to understanding how leaders are represented and how they are successful. Although there is a great deal of knowledge about ILTs in the business context, we know little about professorial leaders while successful leadership is essential to academic performance and success (Tavares et al., 2018). 
When should we know a leader? Socio-cognitive control and computer analysis methods respond to this question using the concept of implicit leadership theories (ICTs) (Hall and Lord, 1995). ILTs are rational constructs or prototypes built from a conception of a leader's characteristics and behaviors (Epitropaki et al., 2013). The relevance of ILTs to leadership is dependent on followers using the prototypes as a criterion to classify others as leaders (Junker and Van Dick, 2014). Followers' attitudes and actions toward leaders are influenced by this categorization process (Epitropaki et al., 2013). When a leader look like his idealized image the most, he will be viewed favorably (Foti et al., 2017).

Research has shown that the general congruence of ILT supporters and recognized leadership attributes are essentially linked to corporate outcomes such as leadership exchange consistency, leadership recognition, corporate engagement, employee satisfaction, and well-being (Epitropaki et al., 2013). Since such work focuses on leading designs in general, nothing is known regarding the importance of increasing a leader's particular trait in the categorization phase. However, the implied inference is that all lead characteristics are equally important for estimating results (Epitropaki et al., 2013). However, they cannot know how many prototypical characteristics could have personally led to these results or which prototype characteristics are most necessary to identify anyone as the chief. Since the prototype of leadership comprises of a set of characteristics that proponents consider members like wisdom, sensitivity, dedication, and dynamism to provide existed in certain dimensions, but well above the prototype, in others (e.g., intelligence), may be considered as comparable to the prototype (Epitropaki and Martin, 2004). However, we suggest that various configurations of attribute levels (i.e., a knowledgeable, arrogant leader vs. a receptive but unintelligent leader) can contribute to specific outcomes for leadership standards. This inference is possible that understanding of the will of the attributes of a leader, when integrated by the supporters, can acquire a strong weight to build an overarching opinion of the leader (Scott et al., 2008).

For instance, suppose one person expects leaders to have eight on a 1 (low) to 9 (high) scale regarding sensitivity and intelligence. Lets assume that this person creates an image of two leaders: the former is seen to be eight sensitive, the latter is four sensitive, and the latter to be eight intelligent. The two members are, on average, numerically similarly distant from the system. Nevertheless, if all other characteristics are kept stable, will such members be similarly prototypically categorized? The conclusion is yes, based on previous work congruence models. Nevertheless, if we believe that some of the leading attributes in the classification procedure, this query's response is not at all (Tavares et al., 2018).

We reason that the construction of leadership discernments outcomes from cognitive algebra (Scott et al., 2008), where the knowledge on leading characteristics earns different weights according to their uncertain importance. However, we think that this is not a pure additive operation. Instead, we claim that Asch (1961) structure model of perception fits the illusion that a leader is formed through supporters. The senses of the individual characteristics rely on other attributes. This more complex interpretation of the printing method is part of the systematic approach to perceptions (Finkel and Baumeister, 2010). Furthermore, we discover that, following the connectionist approach to categorizing leadership, the way followers incorporate knowledge about their leadership characteristics is affected by external factors (Lord and Shondrick, 2011).

Although, ILT studies have helped researchers recognize many leading characteristics of strong prototypic quality, there has been no attempt to examine how identifying such characteristics influence individual leadership expectations experimentally. We use socio-cognitive hypotheses on interpretation procedures and leadership categorization to fill this void to research 
experimental leadership interpretation development dependent on prototypical identification (Tavares et al., 2018). To this end, authors have conjoint analysis (CA). This technique allows manipulation of a multiple variables and the importance of an object's qualities to be evaluated (Rao, 2014). Authors checked the causal relation between identification using CA to evaluate the causal correlation between attribute identification and leadership impression.

We make four main contributions to the literature of ILTs by our manipulations. We first demonstrate that for recognition-based individual leadership standards, the (anti) prototypical features proposed by Epitropaki and Martin (2004) are heterogeneous. Additionally, to lure on a more all-inclusive method to the round of impression (Fiske and Taylor, 2013); we display the essence of leadership perception shaping setup; that is to say, we investigate whether the existence of a certain attribute can strengthen or dilute the effects of other attributes. Fourth, through the distortion of the leadership history (such as the armed, business, and political ones), authors presented the dynamism and consistency between the various leadership structures (Lord et al., 2001). To conclude, researchers presented the benefits of using CA in the exploration of ILTs.

\subsection{ILTs and Leadership Categorization}

Eden suggested the first ideas of Implicit Leadership and Leviatan focused on implicit personality theories. Eden and Leviatan (1975) requested their students to rate the conduct of leadership in a hypothetical situation. The findings (support, facilitation of function, communication facilitation, and target focus) were the same as previous studies. The citizens assessed the members of their respective organizations after examining the factor (Halpin and Winer, 1957). This result suggested that a link between leadership qualities was already in the participants' minds, regardless of whom they were assessing.

A system of leadership was suggested by Lord et al. (2001) to operate on ILTs by utilizing the principles of categorization theory (Rosch and Lloyd, 1978). The prototype of leadership can thus be described as an abstract cognitive framework shaped by the attributes closest to leaders (Epitropaki et al., 2013). Thus, persons are rated as leaders if their traits fit the perceiver's leadership template (Epitropaki et al., 2013).

Logical move in ILT research was to determine the characteristics of this leadership model. Several leading groups' characteristics have been identified (Schyns et al., 2018). The structure proposed by Epitropaki and Martin (2004) is used in our research, which is based on the work of Offermann et al. (1994). Epitropaki and Martin (2004) were interested in increasing the widespread use of ILTs by different groups of workers. Eight original considerations were reduced to six by Offermann et al. (1994), four of which apply to the prototype leader and two to the anti-prototype leader. The prototypes reflect intellect, sensitivity, responsibilities, and complexities, as well as the leader's prototypical traits. Epitropaki and Martin (2004) found that factor structure remained constant over time, with little variation among employee classes.

More recently, the connectionist perspective has emphasized the social influences that affect participants' thinking mechanisms in this leadership categorization philosophy. More precisely, the idea of leadership scheme or product activation (House et al., 2004). Developers that cause specific leadership schemes, depending on contextual factors such as background, perception of the demographic characteristics, gender, the leadership, and the nature of the task. This model helps prototypes of personal leadership to stay flexible and contextually reactive while preserving continuity and accuracy (Shondrick et al., 2010).

However, the areas of ILT are yet to be investigated considering the promising theoreti- 
cal and scientific advances (Foti et al., 2017). We assume that an experimental method will help check the causal impact of these qualities in this area. Previous research examining the influence of leading prototypes has indirectly concluded that ILTs are similarly critical in understanding how individuals perceive others as leaders (Ayuninnisa et al., 2020). These models, however, do not make it possible to determine every attribute's value. Our research tackles this discrepancy by demonstrating how each prototypical trait is understood to affect followers' leadership expectations.

To resolve these problems, we have carried out a series of three research experiments utilizing CA. In First Study, we evaluate the comparative importance of determining their contribution to creativity perceptions by the six ILT factors used by Epitropaki and Martin (2004). Second Study explores how the leader perception is optimized for a more detailed view of this perception's development by testing interactions among ILT factors. In the Third Study, the complexities of the ILTs were finally evaluated to check the heterogeneity in the importance of ILT variables across contexts (e.g., industry, military, social, and political). We briefly present the CA methodology before describing the studies and illustrate how it fits our study resolve (Tavares et al., 2018).

\subsection{Leadership Styles}

The last half century has seen comprehensive leading international work. The scholars have focused so prodigiously because leadership subjects are critical to organizational performance (Kumar, 2007). Members of companies have difficulty achieving competitiveness, efficiency, and a competitive edge without strategic and successful leadership (Gumbe, 2010). Leadership styles have in recent years become a major topic in management, and leadership is viewed by many scholars as an essential variable in motivating how followers of the organization work (Hao et al., 2012). The leadership style was then also found to be a significant indicator of an organization's performance (Bass and Riggio, 2006).

Management is well-known in literature for the beneficial impact of corporate engagement. Commitments have been repeatedly recognized as an important variable in employee comprehension within organizations in organizational literature (Herscovitch and Meyer, 2002). Previous researchers suggest that engagement affects several job-related characteristics, such as determination to stay (Chew and Chan, 2008), absenteeism (Yang, 2015). This is pertinent as organizations with dedicated personnel can circumvent high turnover and absenteeism-associated costs. Additionally, more inspired workers and higher work efficiency are likely to become dedicated (Yang, 2015). The analysis discusses the interaction between Bass and Riggio (2006) and different variables of results (extra employee effort, manager happiness, leadership efficiency) and organizational engagement within the leadership aspects (Transformation and Transaction).

\subsubsection{Autocratic Leadership}

A paradigm shift in the field of leadership theories has taken place throughout history. This philosophy implies that the leader's task is to coerce and rulers since people have an inherent reluctance to function and would not operate whenever possible (Shaw, 1955). This theorem is the concept of autocratic rule. Theory $\mathrm{X}$ often believed that people must be coerced, pressured, or motivated to conduct the organizational tasks and tasks and be supervised, explicitly or threatened with punishment (Shaw, 1955). In this report, autocratic leadership is characterized as a leadership style, where the leader determines directives, strategies, and controls all operations 
without substantive employee participation. The following definitions are specified and their conceptual interpretation (Hackman and Walton, 1986).

Throughout history, a paradigm shift has occurred regarding leadership theories, but autocratic leadership styles are mostly used by the military and law enforcement organizations (Munduate and Medina, 2004). Leaders that use autocratic leadership styles are often referred to as ruling with an iron fist. Authentic coercion and rewarding power to influence others is the basis of autocratic leadership (Munduate and Medina, 2004). Such members are also assertive, authoritarian, and dictatorial in their leadership. However, although this form of management also fits well for unmotivated or troubled staff, that kind of continued usage will contribute to employees' frustration and unproductivity (Lambert, 2002). Leaders should put the needs of their employees first but still maintain loyalty to the organization. The term autocratic leaders sometimes convey negative thoughts. However, for this narrative inquiry research study, it will be viewed as positive and without biases to ensure trustworthy research (Woodard, 2017).

According to Weiskittel (1999), autocratic leadership includes the use of directives or instructions in conjunction with anticipated compliance. The autonomous leader is strong and uses the power to give or deny recompenses and control. Omolayo (2007) argued that autocratic leadership requires the leader to take all decisions, exercise total power, delegate tasks and maintain a master-servant relationship with its dependents. The autocratic dictator only concerns himself with achieving his duties, goals, or objectives. The wishes and interests of the superiors are not considered. Lack of concern for the employee's desires and preferences is not helpful in organizations (Van Vugt, 2006). Theorists have further explored leadership thinking and a robust approach when they change the emphasis of leaders on their employees' participation (Weiskittel, 1999). This model evaluated employee engagement while putting one individual in decision-making and power (Tedesco, 2004).

Autocratic leadership is often used in law enforcement organizations and partakes comparisons to the paramilitary-style method (Schwartz and Cliff, 1993). Orders, discipline, control, administration, and performance are typical of most organizations of law enforcement. Under autocrats, citizens are hired to apply and indoctrinated to conform to a certain leadership style on their first day of work (Schwartz and Cliff, 1993). Autocratic leadership style is the situation where a dictator sets rules, processes and ignores their subordinates' advice or recommendations (Avolio, 1999). Autocratic administration is also seen in businesses, fire services, and the health sector (Tedesco, 2004).

\subsubsection{Democratic Leadership}

Democratic leadership, or mutual leadership, is a form of leadership that includes community participation in decision-making. This kind of leadership may be extended to any organization, from private businesses to colleges, states, and other organizations (Amanchukwu et al., 2015). All have an incentive to join, open sharing of thoughts, and motivation to debate. Although democracy aims to focus on collective unity and the free exchange of information, the community leader provides input and influence. The democratic leader is responsible for deciding who is in the group and who can help in the decisions (Amanchukwu et al., 2015).

Investigators have found that democratic leadership is one of the most productive styles, leading to greater efficiency, better group involvement, and better group moral standards (Guraya et al., 2016). Strong political leaders foster trust and reverence for followers. They are genuine, and based on truth and principles. Supporters continue to be inspired and contribute to society. Strong leaders are always searching for diverse viewpoints and should not seek to suppress dissident views or others from a less common perspective (Iqbal et al., 2015). 
Participatory decision-making often requires political leadership. It provides the staff of management organizations with a firm side. In recent decades, inclusive and participatory leadership or the 'two-name model' has become popular. It is from the thirties and the forty years. Kurt Lewin, a leading behavior expert, undertook experiments to assess the importance of the organization's cooperative/participatory leadership style (Clark and McCabe, 1970). Lewin and his colleagues Ronald Lippitt and Ralph K. White identified in "Leadership and Community Life" the three primary leadership models: egalitarian and autocratic. Lewin, Lippitt, and White argued that the concept of representative government is more popular among the subordinates from interviews with company leaders and staff (Val and Kemp, 2012).

Successful democratic leaders vary in two important ways from autocratic leaders and laissezfaire politicians. Like autocrats, democratic leaders assume individuals reporting to them have thorough expertise and show trust in themselves. Unlike the laissez-faire approach that assigns power to the professionals, the decision-making process includes democratic leaders (Sheshi and Kërçini, 2017). Cooperative / participating members have tremendous responsibilities. Organizations that implement the collaborative design still require sturdy leaders that recognize how to circumvent the downsides as they lose their bearings that can trip collective teams up (Gonos and Gallo, 2013).

\subsubsection{Laissez-Faire Leadership}

Although there was very little debate regarding laissez-faire leadership in the literature (Yang, 2015), laissez-faire leadership was related to negative outcomes, like tension and demotivation, or organizational performance (Avolio, 1999). The laissez-faire style of leadership is known as non-statistical leadership, or non-strategic style at the reverse end of transformation and transactional leadership (Neider and Schriesheim, 2011), multifactor Leadership Questionnaire (MLQ) was adopted for several scientific analyses of laissez-faire leadership (Avolio, 1999)s. As a result, laissez-faire leadership was widely regarded as ineffective, even though most transformational leadership and transactional leadership research emphasizes the efficacy of the two leading models in various ways, including employee job satisfaction and organizational effectiveness (Piccolo et al., 2012). Such studies underline the importance of leadership engagement when laissez-faire leadership is interpreted as a lack of leadership and null leadership due to a failure to provide subordinates' information or guidance (Bass and Riggio, 2006). However, according to this paper, it is not laissez-faire management per se that leads to onedimensional negative outlook and impact, but rather the current value and subsequent evaluation of laissez-faire leadership. To put it another way, management should not always imply rejection, arrogance, disregard, and indifference towards its followers' wishes (Aasland et al., 2010), as stated today. For instance, although a manager / a leader is expected to perform certain tasks like controlling subordinates' success (Podsakoff et al., 2014), there are also incentives for workers to be left isolated with their relations. A leader's personality allows workers to feel valued and confident and demonstrate that leadership has a strong low or uninvolving impact.

Conceivable advantages of less or less involvement in leadership are also provided by principles of dependence (Eisenbeiß and Boerner, 2013), self-control, self-determination (Deci and Ryan, 1980), hegemony (Amundsen and Martinsen, 2014; Ford and Fottler, 1985), and selfleadership (Manz and Sims, 1989). In this way, although rare, some academic work reveals promising effects of laissez-faire leadership in subordinate's innovation capacity because it can promote an innovative environment (Ryan and Tipu, 2013). In other cases, there is a need to approach laissez-faire leadership more suited given possible advantages of non-involvement leadership. Hence this paper redefines the laissez-faire management of the current (negative) 
meaning-ridden concepts with a behavioral focus and discusses why and when the leadership that is laissez-faire can contribute to positive results. This paper aims at this topic by recognizing laissez-faire as an un-leading force and addressing possible moderators of laissez-faire that may deliver successful results (Yang, 2015).

Through addressing these ideas, this paper seeks to add not only to the literature of laissezfaire leadership nonetheless to leadership overall as well. First, concentrating on a leader's "behaviors" (a behavioral component of leadership) in this article is distinct from many current leadership models that have concentrated on "the theory" or "leadership characteristics." A practical structure can enable a more accurate analysis of leadership across different contexts as recognizing the meaning of leadership may involve multiple behavior. Secondly, this paper emphasizes the significance of conditions for efficacy and the degree of leadership effectiveness and extending the concept of situational leadership by reflecting on moderators' role. Although circumstance and contingent leadership emphasize the value of balancing leaders' attitudes and circumstances, this paper highlights the importance of fluvial actions rather than fixed ones by demonstrating certain contextual factors when a leader decides to engage in laissez-faire leadership (as a strategic leadership choice) (Zheng et al., 2010).

\section{Methodology}

The methodology of data analysis and collection are presented in this chapter. Research design, target population, criteria for respondents, and their information are also presented. Additionally, Research scales, scale validity, reliability, and discussion analysis are also mentioned. This research was done based on the posture of a positivist researcher. Positivism observes the social phenomenon, implementing a quantitative strategy with a value-free inclination towards research participants and the generalization of the research results (Saunders et al., 2003).

\subsection{Participants}

Study data collection was performed through cross-sectional surveys. The study's targeted population was the admin and faculty employees of public sector universities in Quetta city, of grade 17 to 19 . The research data collection process was carried out by distribution to targeted university employees of questionnaires. The sampling rule is given by Saunders et al. (2003); a sample of 322 (for people up to 2000 and at 5\% margin of error) was needed. To get this sample size, 350 questionnaires were firstly distributed. Three hundred twenty-eight filled questionnaires were received that present an effective response rate of $65.6 \%$. Mugenda (2003) recommended that a response rate of more than $60 \%$ is good.

\subsection{Materials}

The implicit leadership style scale was taken from Northouse (2019). This scale had eighteen items that made use of a scoring system to determine if the leadership style was autocratic, democratic or laissez faire. The scale was primarily meant to measure the leadership style as told by the leaders, we, nonetheless, used the scale to measure the implicit leadership instead, we used the version developed by Zaman et al. (2017) with some updated in scoring and wording to match an implicit leadership style that was answered by the followers instead. The scale was tested in Balochistan and had shown good results. 
To measure functionality, Functionality Appreciation Scale (FAS) was taken from Alleva et al. (2017). The Functionality scale has 8 items, and a sample item is, . I appreciate my body for what it is capable of doing. All the items from both the scales were organized on a seven-point Likert scale varying from 1 = highly divergent to 7 = firmly accepted to monitor employee opinions. The full scale is provided in the annexure part. The alpha of this size was Cronbach 0.85. In our context, CFA confirmed the validity of the scale.

\subsection{Analysis Approaches}

The research smears at two-step modeling by developing the measurement model before hypothesis testing. According to Hair et al. (2011), the accurate value of reliability and validity avoids interaction between measurement and hypothesis testing.

To determine whether numbers and loadings of estimation (indicator) factors on data support assumptions are checked with the verified factor analysis (CFA) AMOS (Kline, 2005; Zaman et al., 2017). CFA is often believed to be a robust methodology that renders factional properties of postulated calculation models (Anderson and Gerbing, 1988; Goldberg and Velicer, 2006; Hopwood and Donnellan, 2010; Straub et al., 2004), a methodology that enables the analysis of SEM models and frameworks (Thompson, 2013). In a single calculation model, both constructions would be evaluated. The uni-dimensionality, durability, and integrity of the measurement process for the constructs are assessed.

This study's selected constructs are functionality with eight items, Autocratic Leadership, Democratic Leadership and Laissez-Faire leadership with six items each of these three independent variables for the study. The scale is calculated using a minimum of 26 objects. To calculate whether the measured variables are contingent on unobserved or latent variables, a measurement model must be established (Hair et al., 2011). This means that a portion of a formula that determines whether the variables measured depend on the variables not observed, composite or latent' (Abetz et al., 2005) is referred to as the calculation function.

\section{Results}

\subsection{Descriptive Statistics}

The demographic data of respondents is given in table 01. The table demonstrates that out of 322 respondents, 225 were male, and 97 were female. A vast majority of the respondents (209) were grade 18 employees. The designation of respondents ranged from BPS 17-19. 193 employees were faculty members, and 129 were the administrative staff.

\subsection{Correlation Analysis}

As per the results shown in table 2, all the variables are positively correlated with each other, except the Autocratic leadership and Functionality. Such as, Democratic leadership is positively correlated with Functionality, Autocratic leadership, and Laissez-Faire leadership (r $=.297, \mathrm{p}<0.000, .496, \mathrm{p}<0.000$ and $.639, \mathrm{p}<0.000$ respectively). Laissez-Faire leadership with Functionality is $(\mathrm{r}=.144, \mathrm{p}<0.000)$ and with Autocratic leadership $(\mathrm{r}=.231, \mathrm{p}<0.000)$. The Autocratic leadership is negatively correlated with functionality $(\mathrm{r}=-.065, \mathrm{p}=0.12)$ table 02. 
Table 4.1: Descriptive Statistics

\begin{tabular}{lcc}
\hline Variables & Dimensions & Frequency \\
\hline Gender & Male & 225 \\
& Female & 97 \\
Designation & BPS-17 & 104 \\
& BPS-18 & 209 \\
& BPS-19 & 9 \\
Admin/Faculty & Admin & 129 \\
& Faculty & 193 \\
\hline
\end{tabular}

Table 4.2: Correlations

\begin{tabular}{lcccc}
\hline & $\mathbf{1}$ & $\mathbf{2}$ & $\mathbf{3}$ & $\mathbf{4}$ \\
\hline Functional & 1 & & & \\
Autocratic & -0.065 & 1 & & \\
Democratic & $.297^{* * *}$ & $.496^{* * *}$ & 1 & \\
Laissez-Faire & $.144^{* * *}$ & $.231^{* * *}$ & $.639^{* * *}$ & 1 \\
\hline
\end{tabular}

Note: The significance of the correlation shows at ***,*** at $10 \%, 5 \%$ and $1 \%$ respectively.

\subsection{Results of Measurement Models}

AMOS has been used for the study of confirmative factors (CFA). CFA is a statistical technique that examines whether the calculated variables (indicator) are verified in terms of the number of factors and their loadings (Kline, 2005). CFA is often believed to be a robust methodology that renders factional properties of postulated calculation models (Anderson and Gerbing, 1988; Goldberg and Velicer, 2006; Hopwood and Donnellan, 2010; Straub et al., 2004), a methodology that enables the analysis of SEM models and frameworks (Thompson, 2013). Within one calculation process, both constructions are tested (see fig 01). The measurement model for the constructs was evaluated based on the uni-dimensionality, reliability, and validity of the construct.

\subsubsection{Assessment of Uni-dimensionality and Model Fit}

First, in order to attain uni-dimensionality of the constructs, the indicators or items specified to measure a proposed underlying factor should have relatively high-standardized loadings ( 0.50 or greater) on that factor (Hair et al., 2011). Subsequently, the estimated correlations amid the factors should not be greater than 0.85 (Kline, 2005). This study's selected constructs are functionality with eight items, Autocratic Leadership, Democratic Leadership and Laissez-Faire leadership with six items each of these three independent variables for the study. The measuring model consisted of 26 items in total. 
Standardized residual covariance examination indicates that some error terms are correlated with the other error terms in the same construct. The decision was to associate these error terms with fitting the model to explain the better reliability and validity (Hair et al., 2011). Furthermore, the inter-correlation among constructs (factors) is below .85, demonstrating good discriminant validity amid these factors (Kline, 2005). Each item's reliability can be tested by analyzing each measurement's outer loads (items) umrani2018. Researchers have established a retaining guideline for items under which they recommended that objects ranged from 0.40 to 0.70 would be kept (Hair et al., 2011). The 26-point scale and loads of each item suggest that both items reach the level of 0.50 (Table 3). Still, the overall model fails to meet the goodness-of-fit indices benchmark. After correlating the error terms (see fig 01) the data were found to be the acceptable cutoff for the measurement model the $\chi^{2} / \mathrm{df}=2.374$ with $\mathrm{p}=0.000, \mathrm{CFI}=.918, \mathrm{SRMR}=0.072$ and RMSEA= 0.015 (see Table 03).

Table 4.3: Model Fit Index

\begin{tabular}{lccc}
\hline Measure & Estimate & Threshold & Interpretation \\
\hline CMIN/DF & 2.374 & Between 1 and 3 & Excellent \\
CFI & 0.918 & $>0.95$ & Acceptable \\
SRMR & 0.072 & $<0.08$ & Excellent \\
RMSEA & 0.0153 & $<0.06$ & Excellent \\
\hline
\end{tabular}

According to the following principle, the CFA results should be like this given below:

- $\chi^{2} / \mathrm{df}<5$ (Tabachnik and Fidell, 2007)

- Goodness of Fit Index-GFI $\geq .90$ (Baumgartner and Homburg, 1996)

- Comparative Fit Index-CFI $\geq .90$ (Hu and Bentler, 1999)

- Root Mean Square Residual-RMR $\leq .08$ (Hu and Bentler, 1999)

The given values of multiple indices ( $\left.\chi^{2} / \mathrm{df}, \mathrm{CFI}, \mathrm{RMSEA}\right)$ indicate the acceptable range and fit of the dataset to the research model.

\subsection{Reliability and Validity of the Constructs}

As soon as the constructs' uni-dimensionality is achieved, each one is assessed for reliability and validity (De Wulf et al., 2003). Construct reliability (CR) and average variance extraction are used to assess reliability, whereas validity measurement is done using construct, convergent, and discriminant. Using confirmatory factor analysis, (Table 4) shows that based on formulas by Fornell and Larker (NA), the construct reliability (CR) and average variance extracted (AVE) are calculated to confirm the reliability of the constructs further.

Note Composite Reliability (CR) for construct reliability, Average Variance extracted for (AVE) and MSV for convergent validity and Discriminant validity Fornell \& Larcker (1981); the square root of AVE in diagonals with construct correlations values. The significance of the correlation shows at ${ }^{* * *}, * * *$ at $10 \%, 5 \%$ and $1 \%$ respectively. 


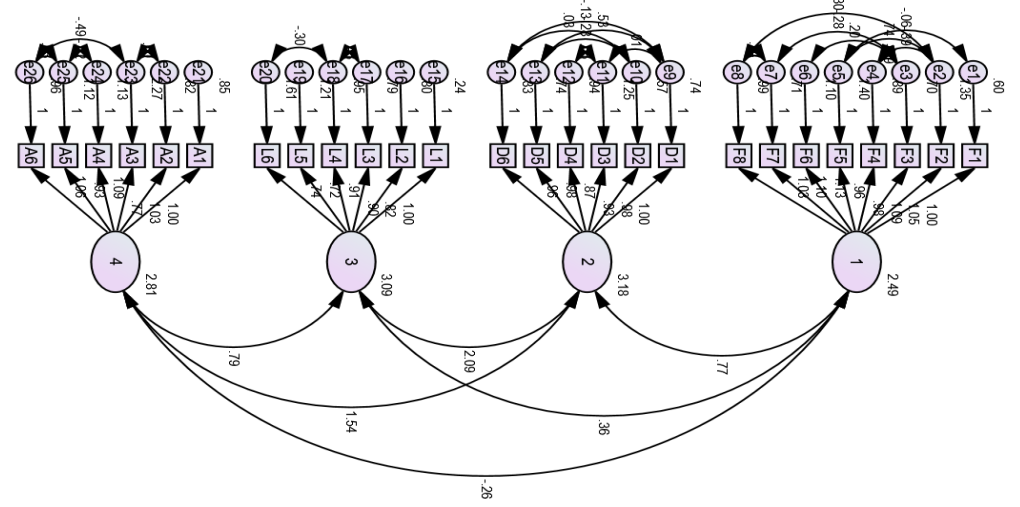

Figure 1: Model Fit Diagram

Table 4.4: Reliability and Validity of Constructs

\begin{tabular}{cccccccc}
\hline CR & AVE & MSV & MaxR(H) & $\mathbf{1}$ & $\mathbf{2}$ & $\mathbf{3}$ & $\mathbf{4}$ \\
\hline 0.958 & 0.739 & 0.075 & 0.961 & $\mathbf{0 . 8 6}$ & & & \\
0.958 & 0.794 & 0.445 & 0.965 & $0.273^{* * *}$ & $\mathbf{0 . 8 9 1}$ & & \\
0.934 & 0.704 & 0.445 & 0.96 & $0.128^{*}$ & $0.667^{* * *}$ & $\mathbf{0 . 8 3 9}$ & \\
0.931 & 0.695 & 0.266 & 0.941 & -0.098 & $0.516^{* * *}$ & $0.267^{* * *}$ & $\mathbf{0 . 8 3 4}$ \\
\hline
\end{tabular}

The CRs above 0.70 and AVEs above 0.50 in all constructs in this study, as suggested by, Bagozzi and Yi (1988) indicate a further improvement to build reliability. The internal consistency (CR) rule, which suggests the threshold 0.7 or more interpretation of a composite reliability coefficient. Table 04 shows that the composite reliability coefficient for each latent variable ranged from 0.931 to 0.958 , indicating that the indicators have sufficient internal consistency reliability (Bagozzi and Yi, 1988; Hair et al., 2011). Fornell and Larker (NA) suggested using average variance to determine convergent validity (AVE). The AVE should be at least 0.50 or higher to imply the convergent validity of a construct. Table 04 shows that all of the constructs in this analysis have a minimum AVE of 0.50 , showed that the study has developed sufficient convergent validity (Chin et al., 1998).

Fornell and Larcker proposed using AVE with a value of 0.5 or higher as a rule of thumb Fornell and Larker (NA). Furthermore, they propose that the AVE's square root should be higher than the correlations among the latent variables when assessing discriminant validity. The AVE for full latent constructs should be above the minimum cutoff of 0.5 , according to Table 4 . Table 04 also reveals that the square root of AVE is greater than the latent variable correlations. As a result, it is possible to assume that all of the tests used in this analysis have sufficient discriminant validity. 


\subsection{Hypothesis Testing}

This research has used multiple regression analysis for hypothesis testing and the significance of the coefficients, Table 5, provides estimates of the multiple regression of three leadership styles (Autocratic, Democratic and Laissez-Faire leadership) on functionality as the dependent variable in the study (Hair et al., 2011). $\mathrm{H}_{1}$ proposed that Autocratic leadership will be negatively related to functionality. Results provided in (Table 05) have revealed a significantly negative association between Autocratic leadership and Functionality $(\beta=-.447, \mathrm{t}=-4.912, \mathrm{p}<$ 0.00). Hence, supporting $\mathrm{H}_{1}$.

The results also report a positive association $\left(\mathrm{H}_{2}\right)$ between Democratic leadership and Functionality with $(\beta=0.669, \mathrm{t}=6.839, \mathrm{p}<0.000)$. Thus, $\mathrm{H}_{2}$ was also supported. Similarly, the results of $\mathrm{H}_{3}$ show that the association between Laissez-Faire leadership and functionality $(=-.175, \mathrm{t}=$ $-1.772, \mathrm{p}=0.077)$; therefore, the negative association among these two variables $\left(\mathrm{H}_{3}\right)$ can also be supported at a $10 \%$ significance level.

Table 4.5: Hypothesis Testing

\begin{tabular}{lcccc}
\hline & & S. E & T-values & P-values \\
\hline Autocratic & -0.447 & 0.091 & -4.912 & 0 \\
Democratic & 0.669 & 0.098 & 6.839 & 0 \\
Laissez-Faire & -0.175 & 0.099 & -1.772 & 0.077 \\
R2 & 0.157 & & & \\
Adj R2 & 0.149 & & & \\
F-stat & 19.44 & & & 0 \\
\hline
\end{tabular}

In order to assess variance explained in the dependent variable (Functionality), important criterion is the R2 value assessment, also called the coefficient of determination (Hair et al., 2011; Henseler et al., 2009).

The R2 is the change in the dependent variable by independent variables, according to different scholars, that can be described by one or more predictor variables (Elliott, 2012; Hair et al., 2011). The appropriate level of $R^{2}$ is subject, following Hair et al. (2011), to the circumstances under which research is carried out.

Falk and Miller (1992) mentioned that a $10 \% R^{2}$ value is acceptable. The value of $R^{2}$ obtained for the present study was 0.157 (see Table 5). This suggests that three leadership styles (Autocratic, Democratic, and Laissez-Faire leadership) explain 15.7 percent of the functionality's variance. As per Falk and Miller (1992) recommendation, the obtained $\mathrm{R}^{2}$ value is acceptable for this study. The F-Statistics is also significant with $(\mathrm{F}=19.44, \mathrm{p}<0.000)$ in Table 5 represents the acceptable model fit for multiple regression.

In Table 6, the VIF value for all three independent variables is less than 3 . This shows no multicollinearity issue for the model, and the estimated coefficients in the multiple regression can be count as an unbiased estimator. 
Table 4.6: Multicollinearity

\begin{tabular}{lcc}
\hline & Tolerance & VIF \\
\hline Autocratic & 0.742 & 1.348 \\
Democratic & 0.463 & 2.158 \\
Laissez-Faire & 0.582 & 1.719 \\
\hline
\end{tabular}

\section{Discussion}

The research comprises three independent variables, i.e., democratic leadership style, autocratic leadership style, laissez-faire leadership style, and one dependent variable, i.e., organizational functionality. All the variables were positively correlated with each other, except the autocratic leadership with functionality. The results achieved uni-dimensionality of the constructs. Indicators or items specified had relatively high-standardized loadings ( 0.50 or greater) on the factors. The estimated correlations between the factors were not greater than 0.85 .

Standardized residual covariance indicated that some error terms were correlated with the other error terms in the same construct. The decision was to associate these error terms with fitting the model to explain better reliability and validity. All constructs in the research had CR of above 0.70 and AVE of at least 0.50 as recommended by Bagozzi and Yi (1988), suggesting further support of the constructs' reliability.

The first hypothesis was formulated to test the negative relationship between the Autocratic leadership style and organizational functionality. A statistically significant relationship has been found between the Autocratic leadership style and organizational functionality (Bagozzi and Yi, 1988).

The second hypothesis tested the positive association between Democratic leadership and organizational functionality and the findings indicate that the relationship was statistically significant (Munduate and Medina, 2004; Van Vugt, 2006; Waterman Jr et al., 1980). Finally, the third hypothesis formulated to test the association between Laissez-Faire leadership and organizational functionality is also found significant (Munduate and Medina, 2004). For Autocratic leadership styles, literature shows how negatively an organization is influenced if the leader is practicing the autocratic leadership style. The subordinates prefer leaving the organization rather than being supervised by an autocratic leader (Van Vugt, 2006). But it was seen in the literature available to telling how subordinates work more carefully if an autocratic leader is supervising them despite their unwillingness showing no relation whether the organization is going functional or vice versa (Blaker et al., 2013).

The third question was whether democratic leadership makes an organization functional for which positive results were received. The positive results were very much predictable because democratic leadership gives guidance to the subordinates and participates in the group, encouraging every group member's involvement in decision-making (Rustin and Armstrong, 2012). So organizational functionality can be very easily associated with democratic leadership style. The fourth question was whether the Laissez-Faire Leadership style makes an organization functional this also resulted in negatively associated organizational functionality. This result was obvious because Laissez-Faire Leadership gives less or no guidance, leaves decisionmaking on the subordinates, and shows little or no involvement in any of their tasks (Rustin 
and Armstrong, 2012).

\subsection{Conclusion}

In the present study, the authors developed a multiple linear regression function to empirically analyze the behavior-based perceived leadership determinants of organizational functionality of the HEIs. The three leadership styles namely Autocratic, Democratic, Laissez-Faire were employed as predictors in the regression model. Primary data gathered from 328 respondents (administrative staff and faculty members) was analyzed through SEM in AMOS 26. The findings indicate that there is a significant relationship between autocratic and democratic leadership styles as determinants of organizational functionality. Moreover, the perceived autocratic leadership style negatively affected organizational functionality and the perceived democratic leadership style positively affected organizational functionality. The effect of Laissez-Faire is found to be statistically insignificant in the study at a 5\% level of significance.

The research led us to multiple findings by looking individually at the three types of leadership. It was seen that the Autocratic leadership style does not make an organization effective. Likewise, the Laissez-Faire Leadership style achieved the same findings. At the same time, the Democratic leadership style was seen adding to the success of an organization.

\subsection{Limitations}

While studying the topic broadly, i.e., seeing all three leadership styles in making an organization functional, we speculated that a quantitative study could generalize the notion to only some extent. For a deeper understanding, we would have to carry out qualitative research on the topic. Autocratic leadership was assumed to be negatively related to organizational functionality, but we have examples of organizations working very efficiently with autocratic leadership. We can perform another study on the organization where autocratic leadership is practiced and how they show functionality under those circumstances.

We were limited to only academic institutions in our research, whereas other sectors can also show different results. Or you are maybe making the results more meaningful. Expanding the research in diverse organizations or organizations where various leadership kinds are practiced simultaneously can show different or same results. We also limited the research to a definite grade/scale of employees. The group members from lower and upper hierarchical order can show how a particular group of employees belonging to a definite group takes leadership as their ruling.

\section{References}

Aarons, G. A., Glisson, C., Green, P. D., Hoagwood, K., Kelleher, K. J., and Landsverk, J. A. (2012). The organizational social context of mental health services and clinician attitudes toward evidence-based practice: a united states national study. Implementation Science, 7(1):1-15.

Aasland, M. S., Skogstad, A., Notelaers, G., Nielsen, M. B., and Einarsen, S. (2010). The prevalence of destructive leadership behaviour. British Journal of management, 21(2):438-452.

Abetz, L., Arbuckle, R., Allen, R. P., Mavraki, E., and Kirsch, J. (2005). The reliability, validity and responsiveness of the restless legs syndrome quality of life questionnaire (rlsqol) in a trial population. Health and quality of life outcomes, 3(1):1-11.

Al-Alawi, A. and Alkhodari, H. J. (2016). Crosscultural differences in managing businesses: applying hofstede cultural analysis in germany, 
canada, south korea and morocco. Elixir International Business Management, 95(2016):4085540861.

Alderfer, C. P. (1980). Consulting to underbounded systems. Advances in experiential social processes, 2:267-295.

Alemu, D. S. et al. (2016). Dysfunctional organization: The leadership factor. Open Journal of Leadership, 5(01):1.

Alemu, D. S. and Shea, D. (2019). A path analysis of diagnosis of organizational levels of functionality: Implications to educational organizations. International Journal of Educational Management.

Alleva, J. M., Tylka, T. L., and Van Diest, A. M. K. (2017). The functionality appreciation scale (fas): Development and psychometric evaluation in us community women and men. Body image, 23:2844.

Alvesson, M. and Sveningsson, S. (2015). Changing organizational culture: Cultural change work in progress. Routledge.

Amah, E. and Ahiauzu, A. (2013). Employee involvement and organizational effectiveness. Journal of Management Development.

Amanchukwu, R. N., Stanley, G. J., and Ololube, N. P. (2015). A review of leadership theories, principles and styles and their relevance to educational management. Management, 5(1):6-14.

Amundsen, S. and Martinsen, Ø. L. (2014). Empowering leadership: Construct clarification, conceptualization, and validation of a new scale. The leadership quarterly, 25(3):487-511.

Anderson, J. C. and Gerbing, D. W. (1988). Structural equation modeling in practice: A review and recommended two-step approach. Psychological bulletin, 103(3):411.

Arrospide, J. J., Hermosilla, D., Yenes, F., and Calvo, I. (NA). Leadership conduct and its consequences for organizations in the basque country. Behavior and Organizational Change, page 167.

Asch, S. E. (1961). Forming impressions of personality. University of California Press.
Ashforth, B. E., Rogers, K. M., Pratt, M. G., and Pradies, C. (2014). Ambivalence in organizations: A multilevel approach. Organization Science, 25(5):1453-1478.

Avolio, B. J. (1999). Full leadership development: Building the vital forces in organizations. Sage.

Ayuninnisa, R., Haqqi, M. F. H., Rusli, N. B., Puteri, N., et al. (2020). Indonesian implicit leadership theory: Typical and positive leadership prototypes for indonesian millennials. Asian Journal of Social Sciences and Management Studies, 7(1):17.

Bagozzi, R. P. and Yi, Y. (1988). On the evaluation of structural equation models. Journal of the academy of marketing science, 16(1):74-94.

Bass, B. M. and Riggio, R. E. (2006). Transformational leadership.

Baumgartner, H. and Homburg, C. (1996). Applications of structural equation modeling in marketing and consumer research: A review. International journal of Research in Marketing, 13(2):139161.

Berelson, B. and Steiner, G. A. (1964). Human behavior: An inventory of scientific findings.

Blaker, N. M., Rompa, I., Dessing, I. H., Vriend, A. F., Herschberg, C., and Van Vugt, M. (2013). The height leadership advantage in men and women: Testing evolutionary psychology predictions about the perceptions of tall leaders. Group Processes \& Intergroup Relations, 16(1):1727.

Boneh, D., Sahai, A., and Waters, B. (2011). Functional encryption: Definitions and challenges. In Theory of Cryptography Conference, pages 253-273. Springer.

Brief, A. P. and Motowidlo, S. J. (1986). Prosocial organizational behaviors. Academy of management Review, 11(4):710-725.

Burke, W. W. and Litwin, G. H. (1992). A causal model of organizational performance and change. Journal of management, 18(3):523-545.

Chemers, M. (2014). An integrative theory of leadership. 
Chew, J. and Chan, C. C. (2008). Human resource practices, organizational commitment and intention to stay. International journal of manpower.

Chin, R. J. (2015). Examining teamwork and leadership in the fields of public administration, leadership, and management. Team Performance Management: An International Journal.

Chin, W. W. et al. (1998). The partial least squares approach to structural equation modeling. Modern methods for business research, 295(2):295-336.

Clark, A. W. and McCabe, S. (1970). Leadership beliefs of australian managers. Journal of Applied Psychology, 54(1p1):1.

Cook, C. J. and Beaven, C. M. (2013). Individual perception of recovery is related to subsequent sprint performance. British journal of sports medicine, 47(11):705-709.

De Wulf, K., Odekerken-Schröder, G., and Van Kenhove, P. (2003). Investments in consumer relationships: A critical reassessment and model extension. The International Review of Retail, Distribution and Consumer Research, 13(3):245-261.

Deal, T. E. and Kennedy, A. A. (1983). Culture: A new look through old lenses. The journal of applied behavioral science, 19(4):498-505.

Deci, E. L. and Ryan, R. M. (1980). Te empirical exploration of.

Den Hartog, D. N. (2015). Ethical leadership. Anпи. Rev. Organ. Psychol. Organ. Behav., 2(1):409-434.

DeRue, D. S. and Ashford, S. J. (2010). Who will lead and who will follow? a social process of leadership identity construction in organizations. Academy of management review, 35(4):627647.

Domagała, O. (2017). The organizational culture as a source of dysfunction in an organization. World Scientific News, 89:32-38.

Eden, D. and Leviatan, U. (1975). Implicit leadership theory as a determinant of the factor structure underlying supervisory behavior scales. Journal of Applied Psychology, 60(6):736.
Eisenbeiß, S. A. and Boerner, S. (2013). A doubleedged sword: Transformational leadership and individual creativity. British Journal of Management, 24(1):54-68.

Elliott, J. (2012). An introduction to sustainable development. Routledge.

Epitropaki, O. and Martin, R. (2004). Implicit leadership theories in applied settings: factor structure, generalizability, and stability over time. Journal of applied psychology, 89(2):293.

Epitropaki, O., Sy, T., Martin, R., Tram-Quon, S., and Topakas, A. (2013). Implicit leadership and followership theories in the wild: Taking stock of information-processing approaches to leadership and followership in organizational settings. The Leadership Quarterly, 24(6):858-881.

Falk, R. F. and Miller, N. B. (1992). A primer for soft modeling. University of Akron Press.

Finkel, E. J. and Baumeister, R. F. (2010). Attraction and rejection.

Fiske, S. T. and Taylor, S. E. (2013). Social cognition: From brains to culture. Sage.

Flamholtz, E. G. and Randle, Y. (2015). Growing pains: Building sustainably successful organizations. John Wiley \& Sons.

Ford, R. C. and Fottler, M. D. (1985). Flexible retirement: Slowing early retirement of productive older employees. Human Resource Planning, 8(3).

Fornell, C. and Larker, D. (NA). Ld (1981). evaluating structural equation models with unobservable variables and measurement error. J Mark Res, pages 39-50.

Forsyth, D. R. and Burnette, J. (2010). Group processes.

Foti, R. J., Hansbrough, T. K., Epitropaki, O., and Coyle, P. T. (2017). Dynamic viewpoints on implicit leadership and followership theories: approaches, findings, and future directions. Leadership quarterly., 28(2):261-267.

Fullwood, R., Rowley, J., and Delbridge, R. (2013). Knowledge sharing amongst academics in uk universities. Journal of knowledge management. 
Gavrea, C., Ilies, L., and Stegerean, R. (2011). Determinants of organizational performance: The case of romania. Management $\mathcal{E}$ Marketing, 6(2).

Goldberg, L. R. and Velicer, W. F. (2006). Principles of exploratory factor analysis. Differentiating normal and abnormal personality, 2:209-337.

Gonos, J. and Gallo, P. (2013). Model for leadership style evaluation. Management: journal of contemporary management issues, 18(2):157-168.

Govan, E., Nicholson, H., and Normington, K. (2007). Making a performance: Devising histories and contemporary practices. Routledge.

Griffin, R. and Moorhead, G. (2011). Organizational behavior: Nelson education.

Gumbe, S. (2010). Leadership skills. The African Executive, 273:1-6.

Guraya, S. Y., Norman, R. I., Khoshhal, K. I., Guraya, S. S., and Forgione, A. (2016). Publish or perish mantra in the medical field: A systematic review of the reasons, consequences and remedies. Pakistan journal of medical sciences, 32(6):1562.

Habib, S., Aslam, S., Hussain, A., Yasmeen, S., and Ibrahim, M. (2014). The impact of organizational culture on job satisfaction, employees commitment and turn over intention. Advances in Economics and Business, 2(6):215-222.

Hackman, J. R. and Walton, R. E. (1986). Leading groups in organizations. Designing effective work groups, 72:119.

Hair, J. F., Ringle, C. M., and Sarstedt, M. (2011). Pls-sem: Indeed a silver bullet. Journal of Marketing theory and Practice, 19(2):139-152.

Hall, R. J. and Lord, R. G. (1995). Multi-level information-processing explanations of followers' leadership perceptions. The Leadership Quarterly, 6(3):265-287.

Halpin, A. W. and Winer, B. J. (1957). a a factorial study of the leader behavior descriptions ${ }^{\mathrm{o}}$. Leader Behavior: Its Description and Measurement, Ohio State University, Bureau of Business Research, Columbus, $\mathrm{OH}$.
Hao, Q., Kasper, H., and Muehlbacher, J. (2012). How does organizational structure influence performance through learning and innovation in austria and china. Chinese Management Studies.

Harper, E., Castrucci, B. C., Bharthapudi, K., and Sellers, K. (2015). Job satisfaction: a critical, understudied facet of workforce development in public health. Journal of Public Health Management and Practice, 21(Suppl 6):S46.

Henseler, J., Ringle, C. M., and Sinkovics, R. R. (2009). The use of partial least squares path modeling in international marketing. In New challenges to international marketing. Emerald Group Publishing Limited.

Herscovitch, L. and Meyer, J. P. (2002). Commitment to organizational change: extension of a three-component model. Journal of applied psychology, 87(3):474.

Hopwood, C. J. and Donnellan, M. B. (2010). How should the internal structure of personality inventories be evaluated? Personality and Social Psychology Review, 14(3):332-346.

House, R. J., Hanges, P. J., Javidan, M., Dorfman, P. W., and Gupta, V. (2004). Culture, leadership, and organizations: The GLOBE study of 62 societies. Sage publications.

Hu, L.-t. and Bentler, P. M. (1999). Cutoff criteria for fit indexes in covariance structure analysis: Conventional criteria versus new alternatives. Structural equation modeling: a multidisciplinary journal, 6(1):1-55.

Hu Juneja, J. (2011). Firsthimanshu, and prachijuneja.". Management." Management Study Guide. WebCraftPvt Ltd.

Iqbal, N., Anwar, S., Haider, N., et al. (2015). Effect of leadership style on employee performance. Arabian Journal of Business and Management Review, 5(5):1-6.

Junker, N. M. and Van Dick, R. (2014). Implicit theories in organizational settings: A systematic review and research agenda of implicit leadership and followership theories. The Leadership Quarterly, 25(6):1154-1173.

Kline, T. (2005). Psychological testing: A practical approach to design and evaluation. Sage. 
Kontić, L. (2012). Applying the weisbord model as a diagnostic framework for organizational analysis. Industrija, 40(2):145-156.

Kotter, J. P. (2008). Corporate culture and performance. Simon and Schuster.

Kuijk, A. (2018). Two factor theory by frederick herzberg. Retrieved [July 1st, 2018] from ToolsHero: https://www. toolshero. com/management/twofactor-theory-herzberg.

Kumar, C. R. (2007). The leadership in management: Understanding leadership wisdom. APH Publishing.

Lambert, L. (2002). A framework for shared leadership. Educational leadership, 59(8):37-40.

Lavy, S., Garcia, J. A., and Dixit, M. K. (2010). Establishment of kpis for facility performance measurement: review of literature. Facilities.

Leavitt, H. J. (1965). Applied organizational change in industry, structural, technological and humanistic approaches. Handbook of organizations, 264.

Levine, J. M. and Moreland, R. L. (2012). A history of small group research: John $\mathrm{m}$. levine and richard 1. moreland. In Handbook of the history of social psychology, pages 382-404. Psychology Press.

López-Domínguez, M., Enache, M., Sallan, J. M., and Simo, P. (2013). Transformational leadership as an antecedent of change-oriented organizational citizenship behavior. Journal of Business Research, 66(10):2147-2152.

Lord, R. G., Brown, D. J., Harvey, J. L., and Hall, R. J. (2001). Contextual constraints on prototype generation and their multilevel consequences for leadership perceptions. The Leadership Quarterly, 12(3):311-338.

Lord, R. G. and Shondrick, S. J. (2011). Leadership and knowledge: Symbolic, connectionist, and embodied perspectives. The Leadership Quarterly, 22(1):207-222.
MalekalketabKhiabani, M. and Abdizadeh, M. (2014). Identifying the key factors of organizational citizenship behaviour in the healthcare industry: Iran perspective. International Journal of Research in Management, 4(4).

Manz, C. C. and Sims, H. P. (1989). Superleadership: Leading others to lead themselves, volume 145. Prentice Hall Press New York.

Marquardt, M. J. (2011). Optimizing the power of action learning. Nicholas Brealey Publishing Boston, MA.

Martin, J. (1992). Cultures in organizations: Three perspectives. Oxford University Press.

Mehmood, K. K., Sonia, F., and Umar, A. (2016). Impact of organic structure on competitive performance of pharmaceutical companies in pakistan: Study of mediating roles. Pakistan Journal of Social Sciences (PJSS), 36(2).

Meijaard, J., Brand, M. J., and Mosselman, M. (2005). Organizational structure and performance in dutch small firms. Small Business Economics, 25(1):83-96.

Middlehurst, R. (1995). Changing leadership in universities. The changing university, pages 7592.

Morton, T. A., Wright, R. G., Peters, K., Reynolds, K. J., and Haslam, S. A. (2012). Social identity and the dynamics of organizational communication. In The handbook of intergroup communication, pages 341-352. Routledge.

Mugenda, O. (2003). \&mugenda a.(2003). Research methods: quantitative and qualitative approaches.

Müller, R. and Turner, R. (2010). Leadership competency profiles of successful project managers. International Journal of project management, 28(5):437-448.

Munduate, L. and Medina, F. (2004). Power, authority, and leadership. Encyclopedia of applied psychology, 10:91-99.

Neider, L. L. and Schriesheim, C. A. (2011). The authentic leadership inventory (ali): Development and empirical tests. The leadership quarterly, 22(6):1146-1164. 
Northouse, P. G. (2019). Introduction to leadership: Concepts and practice. Sage Publications.

Offermann, L. R., Kennedy Jr, J. K., and Wirtz, P. W. (1994). Implicit leadership theories: Content, structure, and generalizability. The leadership quarterly, 5(1):43-58.

Omolayo, B. (2007). Effect of leadership style on job-related tension and psychological sense of community in work organizations: A case study of four organizations in lagos state, nigeria. Bangladesh e-Journal of Sociology, 4(2):30-37.

Oreg, S. and Berson, Y. (2011). Leadership and employeesreactions to change: The role of leaderspersonal attributes and transformational leadership style. Personnel psychology, 64(3):627-659.

Otara, A. (2011). Perception: A guide for managers and leaders.

Piccolo, R. F., Bono, J. E., Heinitz, K., Rowold, J., Duehr, E., and Judge, T. A. (2012). The relative impact of complementary leader behaviors: Which matter most? The leadership quarterly, 23(3):567-581.

Podsakoff, N. P., Podsakoff, P. M., MacKenzie, S. B., Maynes, T. D., and Spoelma, T. M. (2014). Consequences of unit-level organizational citizenship behaviors: A review and recommendations for future research. Journal of Organizational Behavior, 35(S1):S87-S119.

Rao, M. (2014). Transformational leadership-an academic case study. Industrial and Commercial Training.

Rosch, E. and Lloyd, B. B. (1978). Cognition and categorization.

Rustin, M. and Armstrong, D. (2012). What happened to democratic leadership. Soundings, 50(50):59-71.

Ryan, J. C. and Tipu, S. A. (2013). Leadership effects on innovation propensity: A two-factor full range leadership model. Journal of Business Research, 66(10):2116-2129.

Sadler, P. (2001). Leadership and organizational learning. Handbook of organizational learning and knowledge, pages 415-427.
Saunders, M., Lewis, P., and Thornhill, A. (2003). Research methods forbusiness students. Essex: Prentice Hall: Financial Times.

Schein, E. H. (2010). Organizational culture and leadership, volume 2. John Wiley \& Sons.

Schwartz, M. F. and Cliff, M. (1993). An interview with michelle cliff. Contemporary Literature, 34(4):595-619.

Schyns, B., Felfe, J., and Schilling, J. (2018). Is it me or you?how reactions to abusive supervision are shaped by leader behavior and follower perceptions. Frontiers in psychology, 9:1309.

Schyns, B. and Meindl, J. R. (2005). Implicit leadership theories: Essays and explorations. IAP.

Scott, G., Coates, H., and Anderson, M. (2008). Learning leaders in times of change: Academic leadership capabilities for australian higher education.

Seong, S., Kim, Y., and Szulanski, G. (2015). Leadership, innovation, and strategic change: A conversation with michael tushman. Journal of Management Inquiry, 24(4):370-381.

Shaw, M. E. (1955). A comparison of two types of leadership in various communication nets. The Journal of Abnormal and Social Psychology, 50(1):127.

Sheshi, A. and Kërçini, D. (2017). The role of transactional, transformational and participative leadership in performance of sme's in albania. Albanian Journal of Agricultural Sciences, pages 285-292.

Shondrick, S. J., Dinh, J. E., and Lord, R. G. (2010). Developments in implicit leadership theory and cognitive science: Applications to improving measurement and understanding alternatives to hierarchical leadership. The Leadership Quarterly, 21(6):959-978.

Stoller, J. K., Taylor, C. A., and Farver, C. F. (2013). Emotional intelligence competencies provide a developmental curriculum for medical training. Medical teacher, 35(3):243-247.

Stone, K. B. (2015). Burke-litwin organizational assessment survey: Reliability and validity. Organization Development Journal, 33(2). 
Straub, D., Boudreau, M.-C., and Gefen, D. (2004). Validation guidelines for is positivist research. Communications of the Association for Information systems, 13(1):24.

Tabachnik, B. and Fidell, S. (2007). Discriminant analysis. Using multivariate statistics, 6:377-438.

Tavares, G. M., Sobral, F., Goldszmidt, R., and Araújo, F. (2018). Opening the implicit leadership theories black box: An experimental approach with conjoint analysis. Frontiers in Psychology, 9:100.

Tedesco, P. T. (2004). Leadership style comparison: Iowa community college presidents and superintendents and the ideal leadership style perceived by the board of presidents of these organizations. Colorado State University.

Thompson, M. K. (2013). A classification of procedural errors in the definition of functional requirements in axiomatic design theory. In $7 t h$ International Conference on Axiomatic Design (ICAD 2013), volume 32, pages 1-6. Worcester, MA, USA.

Tichy, N. M. (1983). Managing strategic change: Technical, political, and cultural dynamics, volume 3 . John Wiley \& Sons.

Ulrich, D. and Smallwood, N. (2012). What is leadership? In Advances in global leadership. Emerald Group Publishing Limited.

Val, C. and Kemp, J. (2012). Leadership styles. Pathways: the Ontario journal of outdoor education, 24(3):28-31.

Van Vugt, M. (2006). Evolutionary origins of leadership and followership. Personality and Social Psychology Review, 10(4):354-371.

Vigoda-Gadot, E. and Meisler, G. (2010). Emotions in management and the management of emotions: The impact of emotional intelligence and organizational politics on public sector employees. Public Administration Review, 70(1):72-86.
Walton, M. (2007). Leadership toxicity-an inevitable affliction of organisations. Organisations and People, 14(1):19-27.

Waterman Jr, R. H., Peters, T. J., and Phillips, J. R. (1980). Structure is not organization. Business horizons, 23(3):14-26.

Weisbord, M. R. (1976). Organizational diagnosis: Six places to look for trouble with or without a theory. Group \& Organization Studies, 1(4):430447.

Weiskittel, P. (1999). The concept of leadership. Nephrology Nursing Journal, 26(5):467.

Wiseman, N., Ngirande, H., and Setati, S. T. (2017). Existing organizational culture typologies and organizational commitment at a selected higher education institution in south africa. Investment management and financial innovations, (14, 2 (contin. 1)):242-251.

Woodard, T. D. (2017). Autocratic leadership and stress on law enforcement officers: A narrative inquiry. PhD thesis, University of Phoenix.

Yang, I. (2015). Positive effects of laissez-faire leadership: Conceptual exploration. Journal of Management Development.

Zaman, N. U., Bibi, Z., Mohammad, J., and Karim, J. (2017). The mediating role of positive psychological capital between perceived leadership styles and workplace advice network closeness. Pakistan Journal of Commerce and Social Sciences (PJCSS), 11(1):66-89.

Zare, H. and SHEKARCHI, Z. A. R. (2014). The application of tichy's model in iranian public universities.

Zheng, W., Yang, B., and McLean, G. N. (2010). Linking organizational culture, structure, strategy, and organizational effectiveness: Mediating role of knowledge management. Journal of Business research, 63(7):763-771. 